\title{
GL15 and U251 glioblastoma-derived human cell lines are peculiarly susceptible to induction of mitotic death by very low concentrations of okadaic acid
}

\author{
EMILIA CASTIGLI ${ }^{1,2}$, MIRIAM SCIACCALUGA ${ }^{1,2}$, GIANLUCA SCHIAVONI ${ }^{1}$, FLORA BROZZI ${ }^{1,4}$, \\ ROBERTO FABIANI $^{3}$, PAOLO GORELLO ${ }^{1,5}$ and GIAN LUIGI GIANFRANCESCHI ${ }^{1,2}$ \\ ${ }^{1}$ Section of Cellular and Molecular Biology, Department of Cellular and Environmental Biology, \\ ${ }^{2}$ CEMIN (Centro di Eccellenza 'Materiali Innovativi Nanostrutturati'), and ${ }^{3}$ Department of \\ Medical Surgery Specialities and Public Health, University of Perugia, 06100 Perugia, Italy
}

Received July 15, 2005; Accepted August 30, 2005

\begin{abstract}
The challenging possibility of selectively inducing mitotic death in tumor cells by combining genotoxic agents with the inhibition of G2 checkpoints of the cell cycle is the subject of intensive investigation. We show that very low concentrations (3.5 and $5 \mathrm{nM}$ ) of okadaic acid induce mitotic death in two glioblastoma cell lines, in the absence of genotoxic agents. At the concentrations used, the main target of okadaic acid action is protein phosphatase 2A (PP2A), an enzyme deeply involved in the negative control of cell-cycle progression. The peculiar susceptibility of glioblastoma cells to induction of mitotic death by very low concentrations of okadaic acid must be related to an impairment of PP2A activity and to a specific deficiency in some cell-cycle checkpoints. In addition to its ability to induce abnormal mitoses in actively proliferating glioblastoma cells, okadaic acid possesses the ability to force semi-confluent glioblastoma cells to the M phase of the cell cycle, where they show the same abnormalities observed in actively proliferating glioblastoma cells. In semiconfluent cells the induction of mitotic death involves the activity of both the extracellular signal regulated kinases (ERKs) and the M-phase promoting factor: okadaic acid
\end{abstract}

Correspondence to: Dr Emilia Castigli, Section of Physiology and Biophysics, Department of Cellular and Environmental Biology, University of Perugia, Via Pascoli, 06123 Perugia, Italy

E-mail: castigli@unipg.it

Present address: ${ }^{4}$ Department of Experimental Medicine and Biochemical Sciences, Section of Anatomy, ${ }^{5} \mathrm{Hematology}$ and Bone Marrow Transplantation Unit, University of Perugia, Perugia, Italy

Abbreviations: PP2A, protein phosphatase 2A; ERK, extracellular signal regulated kinase; MAPK, mitogen-activated protein kinase; MEK, MAPK kinase; OA, okadaic acid

Key words: glioblastoma, okadaic acid, protein phosphatase 2A, cell cycle overstimulates ERK activity, and PD98059 (inhibitor of ERK activation) as well as roscovitine (S)-isomer (specific inhibitor of M-phase promoting factor activity) counteract the induction of mitotic death. Our results show that, without the use of genotoxic agents, it is possible to induce mitotic death in glioblastoma cells by activating the same uncontrolled pathways responsible for the uncontrolled proliferation.

\section{Introduction}

Glioblastoma is the most aggressive form of malignant gliomas, brain tumors originating from glial cells or their precursors. In the last few decades, some characteristic genetic alterations have been identified and related to specific biochemical pathways involved in the control of cell-cycle progression. The complex pattern derived from these studies indicates that abnormal expression of growth factors and their receptors, defective cell-cycle checkpoints, and activation of antiapoptotic activities contribute to the altered proliferative behaviour of glioblastoma cells. In these cells, the G1 checkpoints are deficient and the tumor suppressor, p53, is often inactive $(1,2)$. Despite the large body of information acquired, an effective therapy of human glioblastoma is still lacking. However, it has been reported that, in several human glioblastomas, the highest degree of apoptosis was detected in the areas with the highest mitotic index suggesting that, during mitosis, some glioblastoma cells are susceptible to spontaneous apoptosis (3).

It has been recently suggested that, during mitosis, tumor cells may be more prone to cell death when a combination of deficient cell-cycle checkpoints and DNA damage occurs (4). This suggests the possibility of sensitizing cancer cells to genotoxic agents by the use of small molecules that inhibit the DNA damage-induced G2 arrest (5). Despite the genomic alterations, tumor cells can overcome the G1 check-point controls and reach the $\mathrm{G} 2$ phase of the cell cycle where residual checkpoint controls are able to avoid mitotic death $(6,7)$. The G2 checkpoints negatively control the activity of the Mphase promoting factor (the complex p34 cdc2 kinase-cyclin B1), the best characterized effector on G2/M transition (8). Therefore, a pharmacological forced activation of the M- 
phase promoting factor could mimic the inhibition of G2phase checkpoints.

In normal conditions, protein phosphatase 2A (PP2A) can constitute a potential negative control of cell-cycle progression through both the G1 phase and the G2 phase (9). In the G1 phase, the involvement of PP2A could be hypothesized given its role in the downregulation of the Ras/ERK (extracellular signal regulated kinase 1/2) pathway (10-12). In this respect, dephosphorylation of MAPK/ERK kinase (MEK) and ERK, performed by PP2A, could constitute a key mechanism in the inactivation of the ERK pathway (13). In several cellular systems, activation of the ERK pathway is strongly related to the induction of proliferation by transcriptionally activating the numerous mitogen-inducible genes regulated by serum response elements (SREs) $(14,15)$. Moreover, it has been demonstrated that ERKs are able, in late G1, to activate the CDK2/cyclin E complex (16) involved in the control of centriole duplication (17) and, in the G2 phase, to cooperate with Polo-like kinase 1 in regulating the translocation of cyclin B1 (the complex cdc2 kinase-cyclin B1) to the nucleus (18). PP2A has been shown to be deeply involved in the downregulation of the M-phase promoting factor (19-22). Therefore, a forced activation of the M-phase promoting factor could be obtained by PP2A inhibition mimicking an overcoming of some cell-cycle checkpoints.

The most widely used inhibitor of PP2A is okadaic acid (OA), a cell permeable polyether fatty acid produced by marine dynoflagellates (23-26). In fact, although several protein phosphatases are sensitive to the inhibitory action of $\mathrm{OA}, \mathrm{PP} 2 \mathrm{~A}$ is the most sensitive.

In cellular systems, the biological effects of OA depend on the cell type and mostly on the concentrations used: OA can act as a tumor promoter but also as an inducer of apoptosis. The OA concentrations able to induce apoptosis in several cell lines are so high that they do not allow the identification of the specific protein phosphatase and, therefore, the mechanism involved.

In order to specifically inhibit PP2A, we analyzed the effects of very low concentrations $(\leq 5 \mathrm{nM})$ of OA on GL15 (27-31) and U251 (32) human glioblastoma cell lines. The main effect was the induction of apoptosis occurring during mitosis

Our results constitute the first demonstration of an apoptotic effect driven by OA at these concentrations and highlight the possibility of identifying glioblastoma-specific biochemical alterations in which the impairment of PP2A is involved. These specific alterations could be the targets for a future pharmacological approach.

\section{Materials and methods}

Cell cultures. Cultures of the GL15 glioblastoma multiforme cell line were grown in minimum essential medium (MEM) supplemented with $10 \%$ heat-inactivated foetal bovine serum (FBS), $100 \mathrm{IU} / \mathrm{ml}$ penicillin $\mathrm{G}, 100 \mu \mathrm{g} / \mathrm{ml}$ streptomycin, $2 \mathrm{mM}$ glutamine and $1 \mathrm{mM}$ sodium pyruvate. Cultures of the U251 glioblastoma cell line were grown in Dulbecco's modified minimum essential medium (DMEM) supplemented with $10 \%$ heat-inactivated FBS, $100 \mathrm{IU} / \mathrm{ml}$ penicillin $\mathrm{G}, 100 \mu \mathrm{g} / \mathrm{ml}$ streptomycin and $2 \mathrm{mM}$ glutamine. The flasks were incubated at $37^{\circ} \mathrm{C}$ in a $5 \% \mathrm{CO}_{2}$ humidified atmosphere. The medium was changed twice weekly and the cells were subcultivated when confluent.

GL15 and U251 cells were treated with 3.5 and $5 \mathrm{nM}$ okadaic acid (Calbiochem) in culture medium, at the indicated times. The other treatments were performed in the same conditions as the okadaic acid treatment. When the combined action of $25 \mu \mathrm{M}$ PD98059 (Calbiochem) with okadaic acid was analysed, the compound was added to the culture medium $30 \mathrm{~min}$ after the inhibitor. The final concentrations of roscovitine (S)-isomer (Calbiochem) and SB203580 (Calbiochem) were $20 \mu \mathrm{M}$ and $10 \mu \mathrm{M}$ respectively. In all experiments, the final concentration of dimethyl sulphoxide (DMSO) was $0.15 \%$. Controls containing the same amount of DMSO were included at each experimental time point.

Morphological analysis of the cells was performed with a contrast phase Nikon microscope. Cell count was performed after trypsinization using a Burker camera.

DAPI staining. Cells were extensively washed with phosphatebuffered saline (PBS) and fixed with $4 \%$ paraformaldehyde for $15 \mathrm{~min}$. After washing with PBS, cells were incubated with $2 \mu \mathrm{g} / \mathrm{ml} \mathrm{4,6-diamidino-2-phenylindole} \mathrm{(DAPI,} \mathrm{Sigma)}$ for $5 \mathrm{~min}$ and dried in air. The preparations were observed using a DMRB Leika microscope.

Indirect immunofluorescence. Cells were extensively washed with PBS, immersed in cold methanol, kept at $-20^{\circ} \mathrm{C}$ for $7 \mathrm{~min}$ and permeabilized by treatment with PBS containing $0.1 \%$ Triton X-100 for $5 \mathrm{~min}$. The cells were then incubated for $60 \mathrm{~min}$ at room temperature with a mouse anti- $\beta$-tubulin antibody (Sigma), diluted 1:50 in PBS containing $0.3 \%$ bovine serum albumin, and washed 3 times with PBS containing $0.1 \%$ Tween-20 and twice with PBS alone. After treatment with fluorescein isothiocyanate (FITC, Sigma) conjugated goat anti-mouse (IgG diluted 1:50 in PBS containing 0.3\% albumin) and washing 3 times with PBS containing $0.1 \%$ Tween-20 and twice with PBS, preparations were incubated with $2 \mu \mathrm{g} / \mathrm{ml}$ DAPI for $5 \mathrm{~min}$ and dried in air. The preparations were observed using a DMRB Leika microscope.

ELISA detection of cytoplasmic nucleosomes. Determination of cytoplasmic histone-associated DNA fragments was performed using the Cell death detection ELISA (PLUS) kit (Roche), following the instructions of the manufacturer. The results are expressed as percentage of optical density, resulting from the activity of peroxidase-conjugated antiDNA-antibody complexed with cytoplasmic nucleosomes of treated cells, compared to the control.

SDS-polyacrylamide gel electrophoresis and immunoblotting. GL15 cell cultures were washed with PBS and scraped with $62.5 \mathrm{mM}$ Tris- $\mathrm{HCl}$ ( $\mathrm{pH} 6.8), 2 \mathrm{mM}$ ethylendiaminetetracetic acid (EDTA), $0.5 \%$ Triton $\mathrm{X}-100$, phosphatase inhibitor cocktail II (Sigma), protease inhibitor cocktail (Sigma), 0.1\% SDS.

The proteins were separated by SDS-PAGE in $10 \%$ acrylamide gel by using the Laemmli method (33) and then transferred to nitrocellulose filters according to Towbin et al (34). Immunolabeling of phosphorylated and total-ERKs was 
performed following the instructions of the manufacturer. The primary antibodies were a mouse anti-phospho-p44/42 MAPK (Thr202/Tyr204) E10 monoclonal antibody and a rabbit anti-p44/42 MAPK antibody (Cell Signaling Technologies) respectively. The secondary antibodies used to detect phosphoand total-ERK content were the peroxidase-conjugated goat anti-mouse immunoglobulins and the peroxidase-conjugated goat anti-rabbit immunoglobulins (Pierce).

Enhanced chemiluminescence detection was performed using the instructions of ECL ${ }^{\mathrm{TM}}$ Western blotting (Cell Signaling Technologies).

Measurements of cell-cycle by flow cytometry. After the different treatments, aliquots of the cell suspension were transferred into centrifuge tubes, washed once with PBS (400 x g, $7 \mathrm{~min}$ ) and successively processed for cell-cycle analysis by propidium iodide (PI)-staining and flow cytometry. Briefly, the cell pellet was resuspended in $0.5 \mathrm{ml}$ of hypotonic fluorochrome solution $(50 \mu \mathrm{g} / \mathrm{ml}$ PI in $0.1 \%$ sodium citrate plus $0.1 \%$ Triton $\mathrm{X}-100$ ) in $12 \times 75-\mathrm{mm}$ polypropylene tubes (Becton-Dickinson, Lincoln Park, NJ). The tubes were kept at $4^{\circ} \mathrm{C}$ for at least $30 \mathrm{~min}$ before flow cytometric analysis. The PI fluorescence of individual nuclei was measured using a FACScan flow cytometer (Becton-Dickinson, Mountain View, CA) at a wavelength of $488 \mathrm{~nm}$. The percentages of the cells in G0/G1, S and G2/M phases were calculated using CellFIT CellCycle Analysis Version 2.0.2. software.

\section{Results}

In the GL15 glioblastoma-derived human cell line, the expression of large $\mathrm{T}$ and thus of small $\mathrm{T}$ antigen of SV40 has been previously demonstrated (35). Therefore, in this cell line the tumor suppressors, $\mathrm{Rb}$ and $\mathrm{p} 53$, are inactivated by the large T antigen (36) and PP2A is partially inactivated by the small T antigen of SV40 (37). In this respect, the biochemical abnormalities derived from SV40 large T antigen expression mirror the behaviour of some human glioblastomas (38).

The effects of $5 \mathrm{nM}$ OA were analysed using several experimental approaches: inspection of cell and nuclear morphology, immunocytochemistry, cell-cycle analysis, and evaluation of cytoplasmic nucleosomes.

Two days after treatment, the analysis of the effects of OA (5 nM) on GL15 cell morphology indicated a strong phenotypical regression characterized by round or polygonal shape and by the absence of process bearing cells, and an induction of cell death characterized by a significant amount of cells which round up and detach from the substrate (data not shown).

The cell count confirmed the induction of cell death: a significant decrease in cell number was observed when the treatment was performed on actively proliferating (1 day of subculturing) as well as on semi-confluent (4 days of subculturing) GL15 cells. The decrease in cell number was $42 \pm 13.8 \%$ SD in actively proliferating and $32 \pm 10 \%$ SD in semi-confluent GL15 cells.

When analysing the effects of OA on nuclear morphology by DAPI staining, the relevant result was the presence of abnormal mitoses, characterized by a scattered distribution of chromosomes, apparent either in metaphase or in anaphase.
Seldom were these abnormal mitoses observed in control cells. In some cases, there was clear evidence that these abnormal mitoses evolved into apoptosis (Fig. 1Aa,b and Ba,b).

These results seem to indicate that $\mathrm{OA}$ induces a kind of cell death which occurs during mitosis. This kind of cell death is sometimes defined as mitotic catastrophe, and it has been recently demonstrated to constitute a special case of apoptosis (39).

Due to the fact that abnormal mitotic spindles may lead to mitotic catastrophe, the spindle morphology was visualized by immunocytochemistry, performed using an anti- $\beta$-tubulin antibody. After treatment with OA, abnormal multipolar or monopolar spindles were observed. In analogy with the results obtained by DAPI staining, abnormal mitotic spindles were seldom observed in the controls (Fig. 1Ac and d).

OA induced an evident increase in the number of mitotic cells (mostly abnormal). In order to quantify this increase, after DAPI staining, we compared the abnormal mitoses in metaphase and anaphase, induced by OA, with normal mitoses in metaphase and anaphase in control cells. The increase was evident when the treatment was performed on actively proliferating and semi-confluent GL15 cells (Fig. 1Ae and Bc). It is interesting to note that the increase is higher in semiconfluent GL15 cells.

In order to get a deeper comprehension of OA effects on GL15 cells, cell-cycle analysis was performed after propidium iodide staining. Two days after treatment, $5 \mathrm{nM}$ OA significantly affected the cell-cycle profiles of both actively proliferating and semi-confluent GL15 cells.

When the treatment was performed on actively proliferating GL15 cells, a significant decrease of the G0/G1 phase of the cell cycle, combined with a significant increase of the subG0/G1 peak, was observed. The other phases of the cell cycle seemed to be slightly affected (Fig. 1Af). Therefore, the main effect appeared to be an induction of apoptosis. It is interesting to note that abnormal mitoses were not detected in the cellcycle profile as an increase of the percentage of cells in the $\mathrm{G} 2 / \mathrm{M}$ phase. The DNA content per cell in the G2/M phase could have been affected by the simultaneous degradation induced by apoptosis. Another possibility is that the increase of the percentage of cells in the M phase was shielded by the simultaneous decrease in the percentage of cells in the G2 phase of the cell cycle.

When the treatment was performed on semi-confluent GL15 cells, a significant decrease in the G0/G1 phase, combined with a significant increase in the $\mathrm{S}$ and $\mathrm{G} 2 / \mathrm{M}$ phases of the cell cycle, was observed (Fig. 1Bd). Therefore, the main effect appeared to be mitotic arrest.

These results could indicate that the apoptotic event shields the mitotic arrest in actively proliferating GL15 cells, while the mitotic arrest prevails in semi-confluent GL15 cells; however, the DAPI staining indicated that the abnormal mitoses, induced by OA, evolved into apoptosis when the treatment was performed on actively proliferating and semiconfluent GL15 cells. Therefore, if the apoptosis evolves from abnormal mitoses, the apoptotic events could be scattered along the whole cell-cycle profile.

In order to confirm this hypothesis, quantitative analysis of cytoplasmic nucleosomes was performed using the ELISA method: our results indicate that, at concentrations of 3.5 and 
A
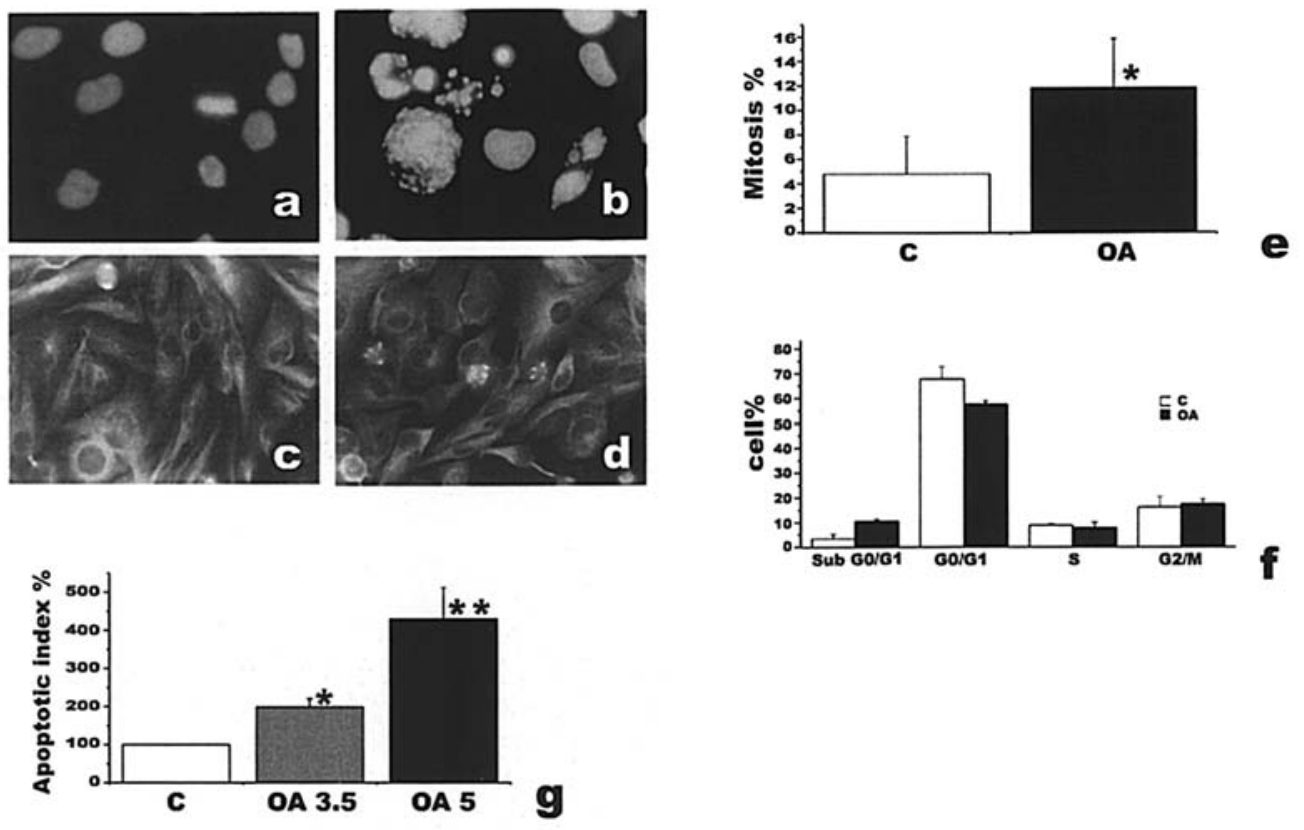

B
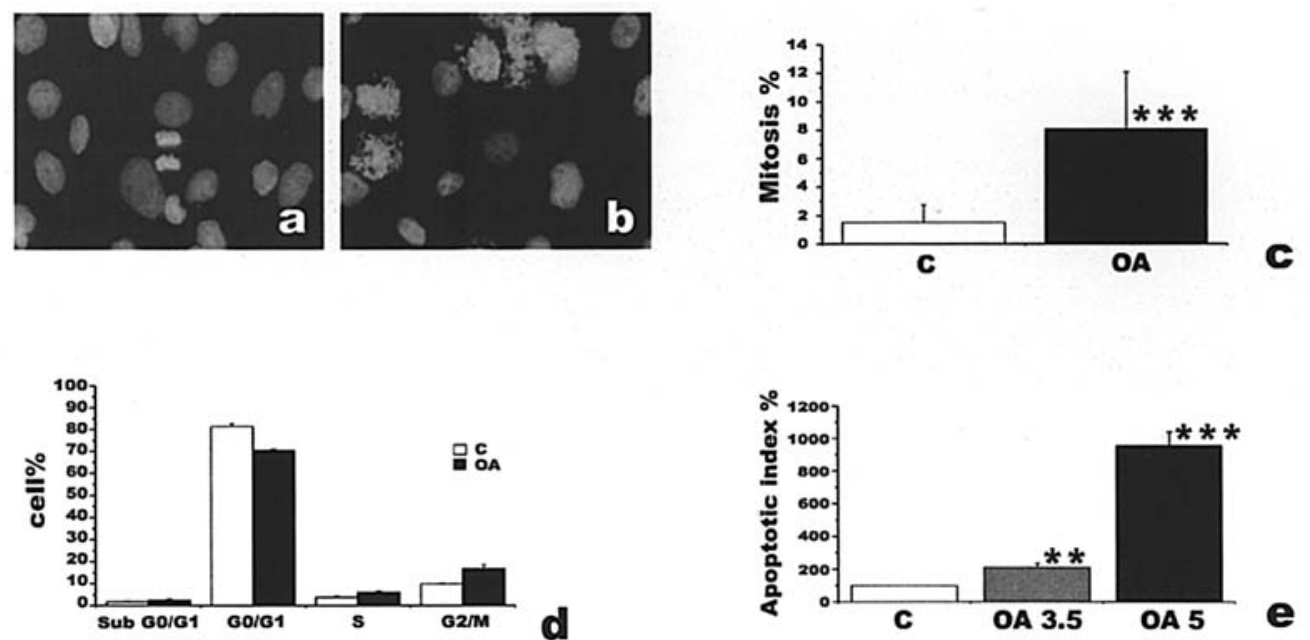

Figure 1. Effects of $5 \mathrm{nM}$ okadaic acid, 2 days after treatment, on GL15 cells. (A) Effects on actively proliferating GL15 cells: a, DAPI staining, control; b, DAPI staining, okadaic acid (original magnification x600); c, immunofluorescence staining of B-tubulin, control; d, immunofluorescence staining of B-tubulin, okadaic acid (original magnification x400); e, percentage of mitotic cells, as evaluated by DAPI staining (C, control; OA, $5 \mathrm{nM}$ okadaic acid); f, analysis of cell cycle evaluated by PI staining and flow cytometry (C, control; OA, $5 \mathrm{nM}$ okadaic acid); g, ELISA detection of cytoplasmic nucleosomes (C, control; OA 3.5, $3.5 \mathrm{nM}$ okadaic acid; OA 5, $5 \mathrm{nM}$ okadaic acid). (B) Effects on semi-confluent GL15 cells: a, DAPI staining, control; b, DAPI staining, okadaic acid (original magnification x600); c, percentage of mitotic cells, as evaluated by DAPI staining (C, control; OA, $5 \mathrm{nM}$ okadaic acid); d, analysis of cell cycle evaluated by PI staining and flow cytometry (C, control; OA, $5 \mathrm{nM}$ okadaic acid); e, ELISA detection of cytoplasmic nucleosomes (C, control; OA $3.5,3.5 \mathrm{nM}$ okadaic acid; OA $5,5 \mathrm{nM}$ okadaic acid). ${ }^{*} \mathrm{P}<0.05,{ }^{* *} \mathrm{P}<0.01,{ }^{* * *} \mathrm{P}<0.001$, Student's t-test.

$5 \mathrm{nM}$, OA induced a significant increase of cytoplasmic nucleosomes on actively proliferating and semi-confluent, GL15 cells (Fig. 1 Ag and Be). This result constitutes a demonstration of the apoptotic effect of OA on GL15 cells.

If the apoptosis induced by OA occurs during mitosis, semi-confluent GL15 cells must be less sensitive to OA action. Semi-confluent GL15 cells, instead, are as susceptible as actively proliferating GL15 cells to the induction of mitotic death induced by OA. The very high percentage of mitotic figures induced by OA in semi-confluent GL15 cells seems to underscore an underlying mitotic stimulus.

Owing to the fact that PP2A is the main target of $5 \mathrm{nM} \mathrm{OA}$, an overactivation of the ERKs and of the M-phase promoting factor could result from PP2A inhibition. Therefore, abnormal activities of ERK1/2 and/or of the M-phase promoting factor were analysed in semi-confluent GL15 cells as possible effectors of OA apoptotic action. Both these activities could be responsible for the hypothesised mitotic stimulus.

Six hours after treatment, OA induced a significant increase in the activity of ERK1/2, as evaluated by using a specific antibody against the double phosphorylated (Thr202/Tyr204) ERK1/2 and by normalyzing with the antitotal-ERK1/2 antibody. This result does not completely identify the increase in ERK1/2 activity as being responsible for the OA apoptotic effect on GL15 cells.

In order to relate the increased ERK activity to the apoptotic effect of OA, experiments with an inhibitor of ERK pathway activation, PD98059 (40), were performed. The increase in 


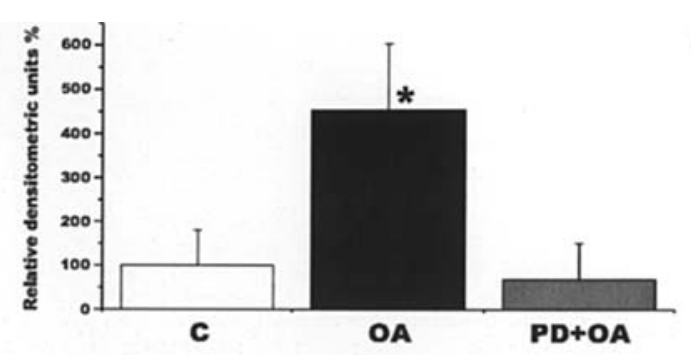

$\mathbf{A}$
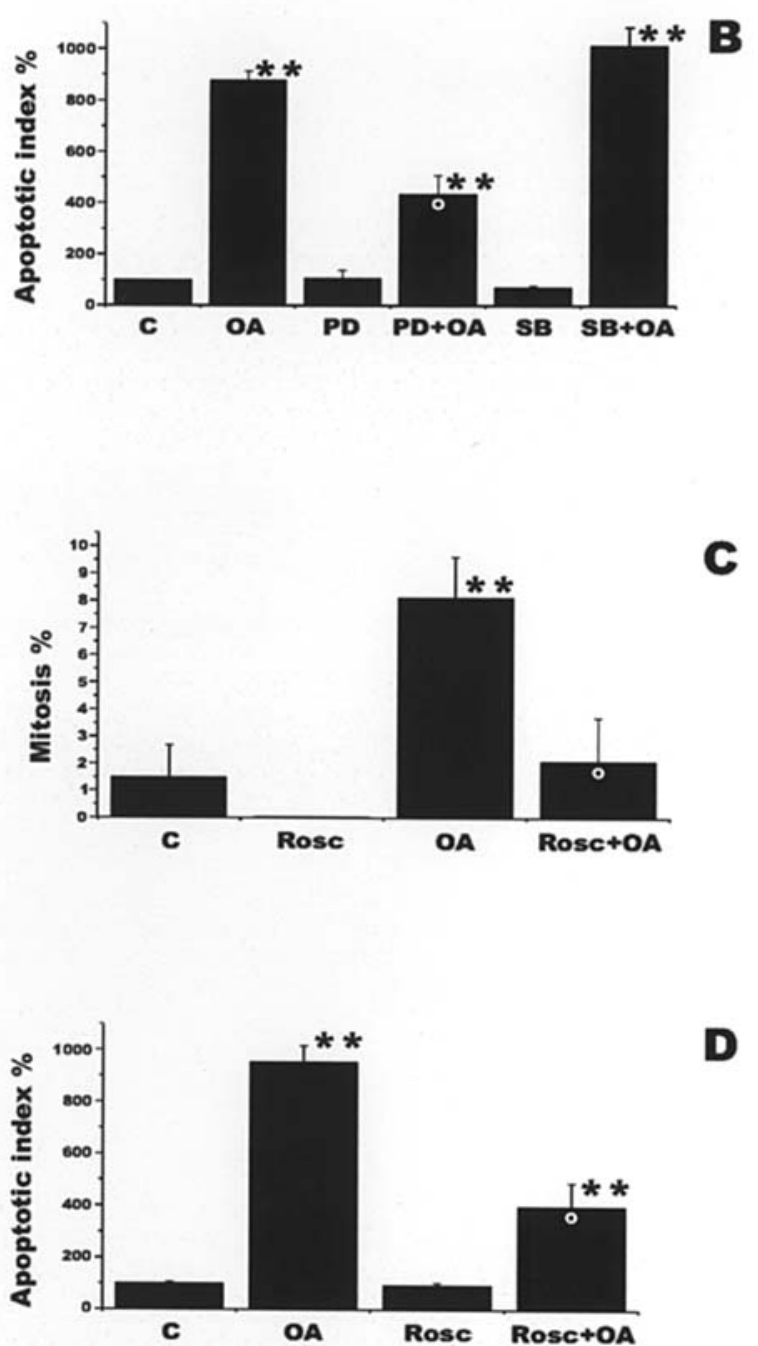

Figure 2. Involvement of ERK activation and of M-phase promoting factor activity in the induction of cell death by $5 \mathrm{nM}$ okadaic acid in semi-confluent GL15 cells. (A) Effects of $5 \mathrm{nM}$ okadaic acid and $25 \mu \mathrm{M}$ PD98059, $6 \mathrm{~h}$ after treatment, on ERK1/2 activity, as evaluated by densitometric analysis of immunoblotting, performed with the anti-phospho-ERK1/2 antibody (C, control; OA, $5 \mathrm{nM}$ okadaic acid; PD + OA, $25 \mu \mathrm{M}$ PD98059 + $5 \mathrm{nM}$ okadaic acid). (B) Effects of $25 \mu \mathrm{M}$ PD98059 and of $10 \mu \mathrm{M}$ SB203580 on the induction of apoptosis by $5 \mathrm{nM}$ okadaic acid, 2 days after treatment $(\mathrm{C}$, control; OA, $5 \mathrm{nM}$ okadaic acid; PD, $25 \mu \mathrm{M}$ PD98059; $\mathrm{PD}+\mathrm{OA}, 25 \mu \mathrm{M}$ PD98059 + 5 nM okadaic acid; SB, $10 \mu \mathrm{M} \mathrm{SB203580;} \mathrm{SB} \mathrm{+} \mathrm{OA,} 10 \mu \mathrm{M}$ $\mathrm{SB} 203580+5 \mathrm{nM}$ okadaic acid). (C) Effects of $5 \mathrm{nM}$ okadaic acid and $20 \mu \mathrm{M}$ roscovitine (S)-isomer, 2 days after treatment, on the percentage of mitotic cells, as evaluated by DAPI staining (C, control; Rosc, $20 \mu \mathrm{M}$ roscovitine (S)-isomer; OA, $5 \mathrm{nM}$ okadaic acid; Rosc $+\mathrm{OA}, 20 \mu \mathrm{M}$ roscovitine (S)isomer $+5 \mathrm{nM}$ okadaic acid). (D) Effects of $20 \mu \mathrm{M}$ roscovitine (S)-isomer on the induction of apoptosis by $5 \mathrm{nM}$ okadaic acid, two days after treatment (C, control; OA, $5 \mathrm{nM}$ okadaic acid; Rosc, $20 \mu \mathrm{M}$ roscovitine (S)-isomer; Rosc + OA, $20 \mu \mathrm{M}$ roscovitine $(\mathrm{S})$-isomer $+5 \mathrm{nM}$ okadaic acid). ${ }^{*} \mathrm{P}<0.05$, ${ }^{* *} \mathrm{P}<0.001$ vs control (Student's t-test); ${ }^{\circ} \mathrm{P}<0.001$ vs okadaic acid (Student's t-test).
ERK phosphorylation, induced by OA, was significantly reduced by PD98059 (Fig. 2A). Along with the inhibition of ERK activity, PD98059 was also able to decrease the number of abnormal mitoses, as evaluated by DAPI staining (data not shown), and to partially counteract the apoptotic effect of $\mathrm{OA}$, as evaluated by the quantitative analysis of cytoplasmic nucleosomes (Fig. 2B). The cell number was comparable when the treatment was performed with OA alone or with OA + PD98059.

Due to the fact that the action of PP2A in the downregulation of the M-phase promoting factor is well documented, the possible involvement of a forced activation of the M-phase promoting factor as an inducer of apoptosis was investigated by using a specific inhibitor of p34 cdc2 kinase, roscovitine (S)-isomer (41).

Roscovitine (S)-isomer partially counteracts the morphological effects of OA on semi-confluent GL15 cells; moreover, when analysing the effects of roscovitine (S)-isomer by DAPI staining, a significant decrease in abnormal mitoses, induced by $\mathrm{OA}$, was observed (Fig. 2C). It is interesting to note that, when the treatment was performed with the roscovitine $(\mathrm{S})$ isomer alone, the result was the total absence of mitotic nuclear morphologies. This finding confirms the inhibition, in GL15 cells, of p34 cdc2 kinase activity because the phosphorylation of nuclear proteins, performed by cdc 2 kinase, is involved in the chromatin condensation at the first stages of mitosis (42).

Roscovitine (S)-isomer significantly counteracted the induction of apoptosis by OA, as evaluated by the ELISA method aimed at quantifying the cytoplasmic nucleosomes (Fig. 2D). The cell number was comparable when the treatment was performed with $\mathrm{OA}$ alone or with $\mathrm{OA}+$ roscovitine $(\mathrm{S})$ isomer.

Due to the fact that an apoptotic action induced by these concentrations of OA has never been reported, we hypothesised that the peculiar sensitivity of GL15 cells was related to the partial inhibition of PP2A by the SV40 small T antigen, but we could not rule out the possibility that this behaviour was related to the peculiar genetic and biochemical alterations typical of glioblastoma cells $(1,43-45)$. Therefore, we analyzed the effects of OA on another human glioblastoma cell line, U251 where, to our knowledge, the expression of large $\mathrm{T}$ antigen of SV40 has never been reported.

Our results show that 3.5 and $5 \mathrm{nM}$ OA was able to induce mitotic arrest and apoptosis, combined with a strong reduction in cell number, in U251 cells. Two days after treatment with $5 \mathrm{nM}$ OA, the DAPI staining showed the presence of abnormal mitoses (Fig. 3A) and a significant increase in the number of mitotic nuclei in metaphase and anaphase, compared to the control (Fig. 3B). Moreover, 2 days after treatment with 3.5 and $5 \mathrm{nM} \mathrm{OA}$, the ELISA method aimed at quantifying the presence of cytoplasmic nucleosomes showed the induction of apoptosis (Fig. 3C). Therefore, the apoptotic response to these concentrations of OA seems to be an intrinsic property of these glioblastoma cell lines.

\section{Discussion}

In this study, we demonstrate that two glioblastoma derived human cell lines are peculiarly susceptible to induction of apoptosis by very low concentrations ( 3.5 and $5 \mathrm{nM}$ ) of OA. 
$\mathbf{A}$

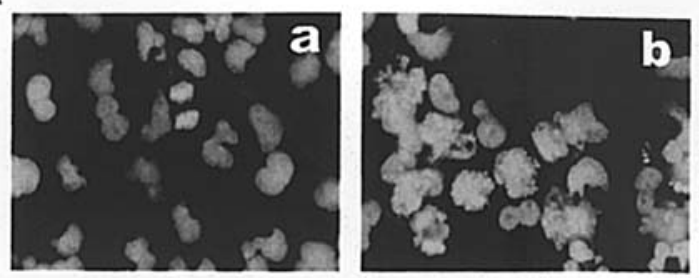

B

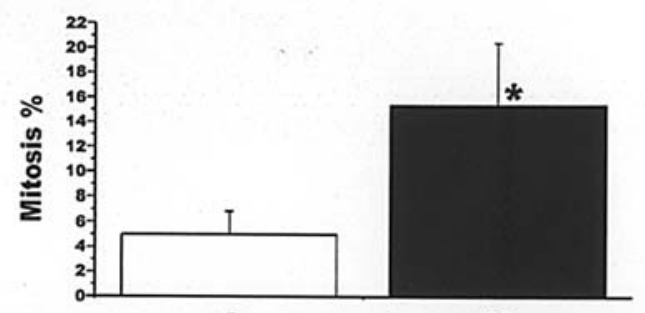

C

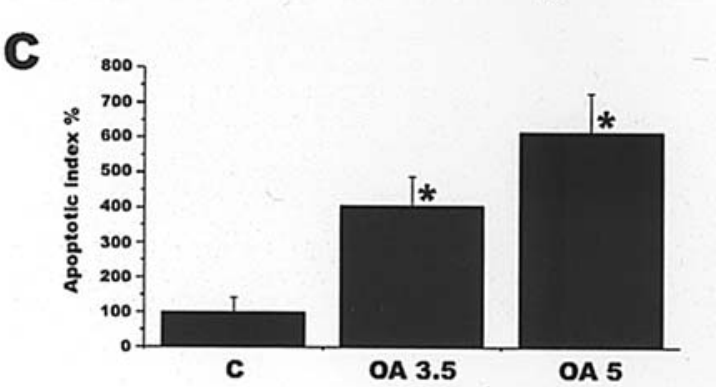

Figure 3. Effects of $5 \mathrm{nM}$ okadaic acid, 2 days after treatment, on U251 cells. (A) Effects on nuclear morphology: a, DAPI staining, control; b, DAPI staining, okadaic acid (original magnification x600). (B) Percentage of mitotic cells as evaluated by DAPI staining (C, control; OA, $5 \mathrm{nM}$ okadaic acid). (C) ELISA detection of cytoplasmic nucleosomes (C, control; OA 3.5, $3.5 \mathrm{nM}$ okadaic acid; OA 5, $5 \mathrm{nM}$ okadaic acid). ${ }^{*} \mathrm{P}<0.001$, Student's t-test.

Although other tumor cell lines, namely Ras-transformed tumor cell lines, have been demonstrated to be peculiarly susceptible to induction of apoptosis by $20 \mathrm{nM} \mathrm{OA}(46)$, the sensitivity of GL15 and U251 glioblastoma cell lines seems exceptional. In principle, while $20 \mathrm{nM}$ OA inhibits both PP2A and PP1A, 3.5 and $5 \mathrm{nM} \mathrm{OA}$ mainly inhibit PP2A.

Analysis of our results shows that, in both cell lines, the main OA effects are the induction of abnormal mitoses, characterized by a scattered distribution of chromosomes, and the induction of apoptosis. OA seems to induce a kind of cell death which occurs during mitosis. This kind of cell death is sometimes defined as mitotic catastrophe, and it has been demonstrated that tumor cells are more prone to this kind of cell death induced by genotoxic agents, probably because of the uncontrolled G1 progression and the lack of some G2 checkpoint controls. The sensitivity of tumor cells to genotoxic agents is increased by a further inhibition of some G2 checkpoint proteins, including p53, 14-3-3, Chk1 and Chk2.

Instead of using genotoxic agents, we used low concentrations of $\mathrm{OA}$ in order to potentially overcome some cell-cycle checkpoints by specific inhibition of PP2A. This experimental approach arose from the fact that, in the G2 phase, although through different biochemical pathways, some $\mathrm{G} 2$ checkpoints and PP2A converge on the inhibition of the M-phase promoting factor maturation. The possibility of selectively inhibiting
PP2A in cellular systems is usually prevented because the expression of PP2A is very high when compared with that of other protein phosphatases (9). It is possible that the peculiar response of GL15 and U251 cells to OA was due to an impairment of PP2A activity in glioblastoma cells.

In several human glioblastoma cells, an impairment of PP2A activity could be due either to chromosomal aberrations, involving the regions in which the genes encoding the PP2A $A \alpha$ or $A \beta$ subunits map $(47,48)$, or to a partial inhibition of PP2A by SV40 small T antigen (37). This impairment of PP2A has been related to the abnormal growth of glioblastoma cells.

PP2A had been proposed to act as a tumor suppressor on the basis of the effects of OA (49), originally identified as a tumor promoter in epithelial cells. Moreover, the involvement of PP2A in control of the Wnt pathway, leading to growth stimulation, has been demonstrated (50).

A strong inhibition of PP2A could be achieved when this enzyme is partially inactive, and our results point out the possibility that this achieved strong inhibition could be responsible for cell death in glioblastoma cells, where some feedback control mechanisms are deficient. In GL15 and U251 cells, along with the uncontrolled G1 progression, the inactivity of the tumor suppressor $\mathrm{p} 53$, has been demonstrated $(35,51)$.

We have shown that, in semi-confluent GL15 cells, the activities of the ERKs and of the M-phase promoting factor are involved in the induction of mitotic death by OA.

The best known effects of ERK activation concern the control of the G1 phase of the cell cycle, and we cannot rule out the possibility that the induction of cell death by OA involves an uncontrolled stimulation of the ERK pathway in this phase of the cell cycle. In semi-confluent GL15 cells, the very high increase of mitotic figures induced by $\mathrm{OA}$ seems to indicate some kind of mitotic stimulus, possibly affecting the $\mathrm{G} 1$ or G2 phase of the cell cycle. Moreover, the involvement of ERKs in the centriole duplication and in the translocation of the M-phase promoting factor to the nucleus has been demonstrated. Therefore, the over-activity of ERKs can contribute to the abnormal maturation of the M-phase promoting factor.

Roscovitine (S)-isomer, the specific inhibitor of M-phase promoting factor activity, significantly inhibited the induction of abnormal mitoses and of apoptosis induced by OA. This result has two main explanations: a) the activity of the M-phase promoting factor is essential for mitotic catastrophe because its inactivity prevents the $\mathrm{G} 2 / \mathrm{M}$ transition; b) the inhibition of PP2A promotes an uncontrolled activation of the M-phase promoting factor, mimicking the inhibition of some G2 checkpoints.

Some reports define the action of OA as mitotic arrest, probably because some OA-sensitive phosphatases have been shown to be involved in the exit from mitosis (52); along with the fact that high OA concentrations did not allow the identification of the specific protein phosphatase involved, it is difficult to explain the observed abnormal mitoses characterised by multipolar spindles as simple mitotic arrest. In fact, centriole duplication does not occur at the end of mitosis. It is interesting to note that ERKs and Polo-like kinase 2 have been shown to control centriole duplication (16,53). Moreover, the cooperation between ERKs and Polo-like kinase 1 has 
been reported (18). In glioblastomas, the overexpression of Polo-like kinase 1 (54) and an abnormal activity of the ERKs (55), combined with altered cell-cycle checkpoints, could be involved in the propensity for aneuploidy. The orchestrated phosphorylation of mitotic substrates, which allows the correct cell-cycle progression, must be altered. A further disengagement between these activities should be the basis for the induction of cell death by OA. In fact, the selective inhibition of PP2A causes an imbalance among the basic mechanisms which control the progression of the cell cycle; this imbalance is counteracted in normal cells by a plethora of pathways, but in glioblastoma cells some of these pathways are lacking.

The identification of these pathways will indicate very specific targets for pharmacological approaches, considering the possibility of inducing apoptosis in tumor cells by overstimulation of the same uncontrolled pathways responsible for the uncontrolled proliferation.

\section{Acknowledgements}

We thank Dr Rosario Donato for kindly providing the U251 cell line and Dr B.J. Richards for the text revision.

\section{References}

1. Maher EA, Furnari FB, Bachoo RM, Rowitch DH, Louis DN, Cavenee WK and De Pinho RA: Malignant glioma: genetics and biology of a grave matter. Genes Dev 15: 1311-1333, 2001.

2. Holland EC: Gliomagenesis: genetic alterations and mouse models. Nat Rev Genet 2: 120-129, 2001.

3. Schiffer D, Cavalla P, Migheli A, Chio A, Giordana MT, Marino S and Attanasio A: Apoptosis and cell proliferation in human neuroepithelial tumors. Neurosci Lett 195: 81-84, 1995.

4. Castedo M, Perfettini J-L, Roumier T, Andreau K, Medema R and Kroemer G: Cell death by mitotic catastrophe: a molecular definition. Oncogene 23: 2825-2837, 2004.

5. Sausville EA, Arbuck SG, Messmann R, Headlee D, Bauer KS, Lush RM, Murgo A, Figg WD, Lahusen T, Jaken S, Jing X, Roberge M, Fuse E, Kuwabara T and Senderowicz AM: Phase I trial of 72-h continous infusion UCN-01 in patients with refractory neoplasm. J Clin Oncol 19: 2319-2333, 2001.

6. Castedo M, Perfettini J-L, Roumier T, Yakushijin K, Horne D, Medema R and Kroemer G: The cell cycle checkpoint kinase Chk2 is a negative regulator of mitotic catastrophe. Oncogene 23: 4353-4361, 2004.

7. Hirose Y, Berger MS and Pieper RO: Abrogation of the Chk-1mediated G2 checkpoint pathway potentiates temozolomideinduced toxicity in a p-53-independent manner in human glioblastoma cells. Cancer Res 61: 5843-5849, 2001.

8. Dunphy WG: The decision to enter mitosis. Trends Cell Biol 4: 202-207, 1994.

9. Janssens V and Goris $\mathrm{J}$ : Protein phosphatase 2A: a highly regulated family of serine/threonine phosphatases implicated in cell growth and signalling. Biochem J 353: 417-439, 2001

10. Seger R and Krebs EG: The MAPK signaling cascade. FASEB J 9: 726-735, 1995.

11. Pearson G, Robinson F, Beers Gibson T, Xu BE, Karandikar M, Berman K and Cobb MH: Mitogen-activated protein (MAP) kinase pathways: regulation and physiological functions. Endocr Rev 22: 153-183, 2001.

12. Kolch W: Meaningful relationships: the regulation of the RAS/ RAF/MEK/ERK pathway by protein interactions. Biochem J 351: 289-305, 2000.

13. Alessi DR, Gomez N, Moorhead G, Lewis T, Keyse SM and Cohen P: Inactivation of p42 MAP kinase by protein phosphatase $2 \mathrm{~A}$ and a protein tyrosine phosphatese, but not CL100, in various cell lines. Curr Biol 5: 283-295, 1995.

14. Gille H, Kortenjann M, Thomae O, Moomaw C, Slaughter C, Cobb MH and Shaw PE: ERK phosphorylation potentiates Elk-1mediated ternary complex formation and transactivation. EMBO J 14: 951-962, 1995.
15. Roovers $\mathrm{K}$ and Assoian RK: Integrating the MAP kinase signal into the G1 phase cell cycle machinery. Bioessay 22: 818-826, 2000 .

16. Nathan H, Keenan M, Bellone C and Baldassare JJ: Stimulation of the Raf/Mek/Erk cascade is necessary and sufficient for activation and Thr-160 phosphorylation of a nuclear targeted CDK2. J Biol Chem 277: 47469-47475, 2002.

17. Tarapore $\mathrm{P}$, Okuda $\mathrm{M}$ and Fukasawa $\mathrm{K}$ : A mammalian in vitro centriole duplication system: evidence for involvement of CDK2/ cyclin E and nucleophosmin/B23 in centrosome duplication. Cell Cycle 1: 75-81, 2002.

18. Yuan J, Eckerdt F, Bereiter-Hahn J, Kurunci-Csacsko E, Kaufmann M and Strebhardt K: Cooperative phosphorylation including the activity of polo-like kinase 1 regulates the subcellular localization of cyclin B1. Oncogene 21: 8282-8292, 2002.

19. Lee TH, Solomon MJ, Mumby MC and Kirschner MW: INH, a negative regulator of MPF, is a form of protein phosphatase $2 \mathrm{~A}$. Cell 64: 415-423, 1991.

20. Lee TH, Turck $\mathrm{C}$ and Kirschner MW: Inhibition of cdc2 activation by INH/PP2A. Mol Biol Cell 5: 323-338, 1994.

21. Kinoshita N, Yamano H, Niwa H, Yoshida T and Yanagida M: Negative regulation of mitosis by the fission yeast protein phosphatase ppa2. Genes Dev 7: 1059-1071, 1993.

22. Clarke PR, Hoffmann I, Draetta G and Karsenti E: Dephosphorylation of cdc 25-C by a type-2A protein phophatase: specific regulation during the cell cycle in Xenopus egg extracts. Mol Biol Cell 4: 397-411, 1993.

23. Bialojan $\mathrm{C}$ and Takai A: Inhibitory effect of a marine-sponge toxin, okadaic acid, on protein phosphatases. Specificity and kinetics. Biochem J 256: 283-290, 1988.

24. Suganuma M, Fujiki H, Suguri H, Yoshizawa S, Hirota M, Nakayasu M, Ojika M, Wakamatsu K, Yamada K and Sugimura T: Okadaic acid: an additional non-phorbol-12-tetradecanoate-13-acetate-type tumor promoter. Proc Natl Acad Sci USA 85: 1768-1771, 1988.

25. Fujiki $H$ and Suganuma $M$ : Tumor promotion by inhibitors of protein phosphatases 1 and $2 \mathrm{~A}$ : the okadaic acid class of compounds. Adv Cancer Res 61: 143-194, 1993.

26. Cohen P, Holmes CFB and Tsukitani Y: Okadaic acid: a new probe for the study of cellular regulation. Trends Biochem Sci 15: 98-102, 1990.

27. Bocchini V, Beccari T, Arcuri C, Bruyere L, Fages C and Tardy M: Glial fibrillary acidic protein and its encoding mRNA exibit mosaic expression in a glioblastoma multiform cell line of clonal origin. Int J Dev Neurosci 11: 485-492, 1993.

28. Arcuri C, Bocchini V, Guerrieri P, Fages C and Tardy M: PKA and $\mathrm{PKC}$ activation induces opposite glial fibrillary acidic protein (GFAP) expression and morphology changes in a glioblastoma multiform cell line of clonal origin. J Neurosci Res 40: 622-631, 1995.

29. Moretto G, Brutti N, De Andelis V, Arcuri C and Bocchini V: A time-dependent increase in glial fibrillary acidic protein expression and glutammine synthetase activity in long-term subculture of the GL15 glioma cell line. Cell Mol Neurobiol 17: 509-519, 1997.

30. Castigli E, Arcuri C, Giovagnoli L, Luciani R, Giovagnoli L, Secca T, Gianfranceschi GL and Bocchini V: Interleukin-1B induces apoptosis in GL15 glioblastoma-derived human cell line. Am J Physiol 279: C2043-C2049, 2000.

31. Guillamo JS, Lisovoski F, Christov C, Le Guerinel C, Defer GL, Peschanski $\mathrm{M}$ and Lefrancois T: Migration pathways of human glioblastoma cells xenografted into the immunosuppressed rat brain. J Neurooncol 52: 205-215, 2001.

32. Rutka JT, Ivanchuk S, Mondal S, Taylor M, Sakai K, Dirks P, Jung P, Berker LE and Ackerley C: Co-expression of nestin and vimentin intermediate filaments in invasive human astrocytoma cells. Int J Dev Neurosci 17: 503-515, 1999.

33. Laemmli UK: Cleavage of structural protein during the assembly of the head of bacteriophage T4. Nature 227: 680-685, 1970.

34. Towbin H, Staelin T and Gordon J: Electrophoretic transfer of protein from polyacrylamide gels in nitrocellulose sheets. Procedure and some applications. Proc Natl Acad Sci USA 76: 4350-4354, 1970.

35. Tognon M, Casalone R, Martini F, De Mattei M, Granata P, Minelli E, Arcuri C, Collini P and Bocchini V: Large T antigen coding sequences of two DNA tumor viruses, BK and SV40, and non-random chromosome changes in two glioblastoma cell lines. Cancer Genet Cytogenet 90: 17-23, 1996.

36. Chen W and Hahn WC: SV40 early region oncoproteins and human cell transformation. Histol Histopathol 18: 541-550, 2003. 
37. Yang SI, Lickteig R, Estes R, Rundell K, Ealter G and Mumby MC: Control of protein phosphatase $2 \mathrm{~A}$ by simian virus 40 small-t antigen. Mol Cell Biol 11: 1988-1995, 1991.

38. Martini F, De Mattei M, Iaccheri L, Lazzarin L, BarbantiBrodano G, Tognon M and Gerosa M: Human brain tumors and simian virus SV40. J Natl Cancer Inst 87: 1331, 1995.

39. Castedo M, Perfettini J-L, Roumier T, Valent A, Raslova H, Yakushijin K, Horne D, Feunteun J, Lenoir G, Medema R, Vainchenker W and Kroemer G: Mitotic catastrophe constitutes a special case of apoptosis whose suppression entails aneuploidy. Oncogene 23: 4362-4370, 2004

40. Alessi DR, Cuenda A, Cohen P, Dudley DT and Saltiel AR: PD098059 is a specific inhibitor of the activation of mitogen activated protein kinase in vitro and in vivo. J Biol Chem 270: 27489-27494, 1995.

41. Havlicek L, Hanus J, Vesely J, Leclerc S, Meijer L, Shaw G and Strnad M: Cytokinin-derived cyclin-dependent kinase inhibitors: synthesis and cdc2 inhibitory activity of olomoucine and related compounds. J Med Chem 40: 408-412, 1997.

42. Ohi RV and Gould KL: Regulating the onset of mitosis. Curr Opin Cell Biol 11: 267-273, 1999.

43. Bocchini V, Casalone R, Collini P, Rebell G and Lo Curto F: Changes in glial fibrillary acidic protein and karyotype during culturing of two cell lines established from human glioblastoma multiform. Cell Tissue Res 265: 73-81, 1991.

44. Misra A, Pellarin M, Shapiro JR and Feuerstein BG: A complex rearrangement of chromosome 7 in human astrocytoma. Cancer Genet Cytogenet 151: 162-170, 2004.

45. Kubota H, Nishizaki T, Harada K, Harada K, Oga A, Ito H, Suzuki M and Sasaki K: Identification of recurrent chromosomal rearrangements and the unique relationship between lowlevel amplification and translocation in glioblastoma. Genes Chromosomes Cancer 31: 125-133, 2001.

46. Rajesh D, Schell K and Verma AK: Ras mutation, irrespective of cell type and p53 status, determines a cell's destiny to undergo apoptosis by okadaic acid, an inhibitor of protein phosphatase 1 and 2A. Mol Pharmacol 56: 515-525, 1999.
47. Colella S, Ohgaki H, Ruediger R, Yang F, Nakamura M, Fujisawa H, Kleihues $P$ and Walter G: Reduced expression of the $\mathrm{A} \alpha$ subunit of protein phosphatase $2 \mathrm{~A}$ in human gliomas in the absence of mutations in the $A \alpha$ and $A \beta$ subunit genes. Int $J$ Cancer 93: 798-804, 2001.

48. Nakamura M, Yang F, Fujisawa H, Yonekawa Y, Kleihues P and Ohgaki H: Loss of heterozygosity on chromosome 19 in secondary glioblastomas. J Neuropathol Exp Neurol 59: 539-543, 2000.

49. Walter G and Mumby M: Protein serine/threonine phosphatases and cell transformation. Biochim Biophys Acta 1155: 207-226, 1993.

50. Seeling JM, Miller JR, Gil R, Moon RT, White R and Virshup DM: Regulation of beta-catenin signaling by the B56 subunit of protein phosphatase 2A. Science 283: 2089-2091, 1999.

51. Asai A, Miyagi Y, Sugiyama A, Gamanuma M, Hong SH, Takamoto S, Nomura K, Matsutani M, Takakura K and Kuchino Y: Negative effects of wild-type p53 and s-Myc on cellular growth and tumorigenicity of glioma cells. Implication of the tumor suppressors genes for gene therapy. J Neurooncol 19: 259-268, 1994.

52. Vandre DD and Wills VL: Inhibition of mitosis by okadaic acid: possible involvement of a protein phosphatase $2 \mathrm{~A}$ in the transition from metaphase to anaphase. J Cell Sci 101: 79-91, 1992.

53. Hoffmann I: Playing polo in G1: a novel function of polo-like kinase-2 in centriole duplication. Cell Cycle 3: 1230-1231, 2004.

54. Dietzmann K, Kirches E, von Bossanyi P, Jachau K and Mawrin C: Increased human polo-like kinase-1 expression in gliomas. J Neurooncol 53: 1-11, 2001.

55. Mandell JW, Hussaini IM, Zecevic M, Weber MJ and Vandenberg SR: In situ visualization of intratumor growth factor signaling. Immunohistochemical localization of activated ERK/ MAP kinase in glial neoplasms. Am J Pathol 153: 1411-1423, 1998 